\section{La Arqueología de la Arquitectura en el siglo $\mathrm{xxI}^{1}$}

\section{Archaeology of Architecture in the 21st century}

Agustín Azkarate Garal-Olaun

Universidad del País Vasco *

\section{Resumen}

Tras veinte años de eufórica puesta en marcha de la llamada Arqueología de la Arquitectura, distintas reflexiones llaman la atención sobre su trayectoria futura, preocupadas por las limitaciones de su campo de estudio y por la supuesta pobreza de su aplicación. Al contrario, el bagaje instrumental de la AA y su manera «arqueológica» de ver la cultura construida, como demuestra su rica experiencia, permiten aventurar su apertura a un amplio campo de propuestas epistemológicas.

Palabras clave: Vitrubio, arqueología de la complejidad, [household archaeology, spatial sintaxis], Latinoamérica.

\section{Abstract \\ Twenty years after the starting of the so-called Archaeology of Architecture, different proposals have focused on its coming development, worried about the limits of its field study and supposed scanty application. This work, on the contrary, intends to show that the instrumental background of the Archaeology of Architecture together with its archaeological way of analysing the building culture, as its experience shows, enable saying that a wide field of epistemological proposals is still to be open.}

Key Words: Vitrubius, archaeology of complexity, household archaeology, spatial syntax, Latin America.

fgpazgaa@vc.ehu.es.
Han transcurrido ya dos décadas desde que R. Francovich y R. Parenti editaran los resultados del ciclo de conferencias impartido el año anterior en la Certosa di Pontignano de Siena ${ }^{2}$. Considerado como el final de un decenio de experiencias en el ámbito de la arqueología aplicada al conocimiento de la arquitectura, definido incluso como la «asamblea constituyente» del análisis estratigráfico aplicado a los alzados ${ }^{3}$, aquel encuentro apuntó también las principales líneas de investigación que iba a seguir la Arqueología de la Arquitectura (AA) hispano-italiana durante los veinte años siguientes.

Por aquellas fechas, a la vez que iban efectuándose las oportunas correcciones a los principios estratigráficos «harrisianos», derivadas de la especificidad del contexto arquitectónico, se iba ampliando también la «óptica visual» de la disciplina hacia ámbitos cada vez más diversificados. El resultado fue una suma de experiencias -creemos que fecunda aunque desigual- que priorizó determinadas temáticas de naturaleza instrumental, tecnológica y funcional, en detrimento de otras de carácter social y simbólico. Como consecuencia quizá de este tratamiento asimétrico, últimamente vienen manifestándose algunas actitudes críticas frente a la AA.

Algunas de ellas nos parecen pertinentes por su naturaleza constructiva y renovadora: las advertencias, por ejemplo, que algunos autores hacen sobre el excesivo peso de las orientaciones funcionalistas (incluso histórico-culturales) en la AA de la Europa meridional y su reivindicación de las dimensiones sociales y simbólicas de los espacios construidos deben considerarse no sólo saludables sino necesarias para el futuro de la disciplina ${ }^{4}$.

Otras, en cambio, nos parecen más preocupantes y no tanto por la intencionalidad de quienes las expresan cuanto por la interpretación casi epitáfica que de su lectura pueden hacer algunos otros. G. P. Brogiolo, en un trabajo reciente de gran interés ${ }^{5}$, reflexiona sobre la trayectoria de

\footnotetext{
${ }^{1}$ Para ver con mayor extensión los argumentos desarrollados en este breve artículo, cfr. Azkarate, A. (e.p.), La Arqueología de la Arquitectura como Arqueología de la Arquitectura, en Quirós Castillo, J. A. (ed.), El fin de la Arqueología. La Arqueología en los inicios del siglo XXI, Ed. Siglo XXI, Madrid.

${ }^{2}$ Francovich, R. y Parenti, R. (a cura di), (1988), Archeologia e restauro dei monumenti, (Siena, 1987), Florencia.

3 Brogiolo, G. P. (1996), Prospettive per l'archeologia dell'architettura, Archeologia dell'architettura, I, pp. 11 ss.; Brogiolo, G. P. (1997), Dall'analisi stratigrafica degli elevati all'Archeologia dell'Architettura, Archeologia dell'Architettura, II, pp. 181 ss.

${ }^{4}$ Criado, F. (1999), Del Terreno al Espacio: Planteamientos y perspectivas para la Arqueología del Paisaje, CAPA, 6, Santiago de Compostela; Mañana, P., Blanco, R. y Ayán, X. M. (2002), Arqueotectura, 1: Bases teórico-metodológicas para una Arqueología de la Arquitectura, TAPA, 25, Santiago de Compostela. 5 Brogiolo, G. P., (2007), Dall'Archeologia dell'architettura all'Archeologia della complessità, Pyrenae, 38, vol. 1, pp. 2-39.
} 
la AA en Italia: cuenta este autor cómo - frente a la «historia de la arquitectura» y a su larga tradición en el estudio de «monumenti di qualità architettonica superiore, dei quali ha ricercato e classificato in primo luogo le tipologie e gli stili»— la aplicación de los métodos arqueológicos a la arquitectura (léase $\mathrm{AA}$ ) en los años 70 «è invece partita... da una prospettiva contrapposta, quella della cultura materiale delle classi subalterne». Esta perspectiva a la que se refiere Brogiolo — que hay que situar, además, en el contexto ideológico neopositivista y neomarxista ${ }^{6}$ que iba a caracterizar a la renovación de la Arqueología Medieval italiana (cfr. Archeologia Medievale, 1974)— acabó convirtiéndose en un corsé asfixiante ${ }^{7}$ que, a la hora de encarar ambiciosos proyectos como el Corpus delle chiese altomedievali europee/Corpus of early medieval churches in Europe, obligaba a «operare al di fuori degli schemi teorici dell'Archeologia dell'Architettura ${ }^{8}$.

La insuficiencia de estos esquemas teóricos lleva a este autor a plantear de nuevo «l'irrisolte questione se lo studio stratigrafico delle architteture debba essere considerato solo un metodo, uno strumento per reconstruire la sequenza di un edificio o se possa diventare una disciplina autonoma che, a partire dalla sequenza, prevenga a ricostruzioni storiche più generali, sia di tipo tradizionale (storia delle tecnologie, dell'uso politico, del valore economico), sia nelle interpretazioni dei significati simbolici, rinnovate dall'archeologia porstprocessuale»'.

Al optar, lógicamente, por la segunda de las alternativas, propone dar el salto "dall'Archeologia dei segmenti, quali sono l'Archeologia dell'architettura e le tante etichette inventate dal nulla in questi anni di fervorosa e talora immaginativa recerca teorica del solco dell'Archeologia post.processuale»... a "uñArcheologia della complessità $e$ delle relazioni» ${ }^{10}$.

\footnotetext{
${ }^{6}$ Ibidem, p. 8

7 Ya lo había advertido el propio A. Carandini cuando reprochaba amistosamente a los arqueólogos medievalistas el ocuparse únicamente de todo aquello que parecía no interesar a los historiadores del arte, potenciando la identificación del arqueólogo con la ruina y dejando el estudio de los grandes edificios en uso al arbitrio de los historiadores del arte y su restauración o modificación en manos de los arquitectos restauradores: «Io vorrei invece Ricado Francovich fare la storia di Palazzo Vecchio o la storia di una delle più grandi cattedrali o chiese d'Italia... C'è quindi bisogno di una presa diretta dell'archeologia sui grandi temi sia dei singoli oggetti sia dei monumenti, per dimostrare la sua capacità $e$ le sue potenzialitè ai massimi livelli di complessità», Carandini, A. (1988), "Archeologia, Architettura, Storia dell'Arte», en Francovich, R. y Parenti, R. (coord.), Archeologia e restauro di monumenti, Florencia, p. 36. Cfr. También Carandini, A. (1997), Historias en la tierra. Manual de excavación arqueológica, Barcelona, p. 227.

8 Brogiolo, A. (2007), p. 11.

9 Ibidem, p. 9.

${ }^{10}$ Ibidem, pp. 32-33.
}

Creemos que la diversidad semántica de los espacios construidos no constituye un planteamiento de reciente gestación, ni hay por qué reivindicarlo como una novedad conceptual. Cuando se reclama la multidimensionalidad de los entornos construidos como espacios físicos, espacios sociales y espacios simbólicos ${ }^{11} \mathrm{y}$, consecuentemente, se propone la reconstrucción histórica de lo que se consideran tres subconjuntos interrelacionados - los espacios de trabajo, los espacios de habitación y los espacios ideológi$\cos ^{12}$ - no se hace sino recuperar el pensamiento vitrubiano cuando aludía a los tres principios que debían regir la arquitectura: la firmitas, como expresión de las capacidades socioeconómicas y tecnológicas de una sociedad para proveerse de materias primas, extraerlas, transformarlas, transportarlas y aparejarlas; la utilitas, como reflejo de organización social, política y religiosa necesitada de articular unos espacios de funcionalidades y significados diversos; y finalmente la venustas, como plasmación de su pensamiento, de su ideología ${ }^{13}$.

Aún reconociendo que la tentación del nominalismo es, sin duda, un rasgo consustancial al proceso investigador, resulta difícil evitar cierta sensación de recurrencia en este tipo de propuestas, resultado quizá de «la neblina característica de una amnesia moderna, que conduce a gestos intelectuales repetitivos ${ }^{14}$.

Es cierto que la praxis cotidiana ha acabado circunscribiendo la AA frecuentemente a su vertiente más instrumental y es cierto también, como apunta Brogiolo, que la AA «ha gli strumenti e metodologici per indagare sia gli spazi del lavoro, sia quelli abitativi, sia quelli ideologici»... ma da sola... non è in grado di ricostruire una storia esaustiva» ${ }^{15}$. Pero también es verdad que la AA posee una rica trayectoria historiográfica (no conocida suficientemente) en la que han convivido - y conviven - diversas corrientes epistemológicas y que sólo hemos de reivindicar y poner en práctica la naturaleza interdisciplinaria y mestiza que siempre le ha caracterizado ${ }^{16}$.

\footnotetext{
${ }^{11}$ Civantos, J. M. (2006), Il territorio stratificato: proponte dall'archeologia del paesaggio, en Francovich, R. y Valenti, M. (ed.), IV Congresso Nazionale di Archeologia Medievale, Firenze, pp. 3-7.

12 Brogiolo, A. (2007), p. 31.

13 Latorre, P. (1996), La arqueología de la arquitectura. Consecuencias metodológicas de su aplicación al proyecto de restauración, en Caballero, L. y Escribano, C. (eds.), Actas Arqueología de la Arquitectura, Burgos, p. 108; Azkarate, A. (2001).

14 Witmore, C. (2007), Arqueología simétrica: un manifiesto breve, Complutum, Vol. 18, pp. 305-319.

15 Brogiolo, A. (2007), p. 32.

${ }^{16}$ Los párrafos siguientes proceden, con alguna modificación, de Azkarate, A., La Arqueología de la Arquitectura como Arqueología de la Arquitectura, cit.
} 
- En Europa meridional, T. Mannoni «acuñó» el nombre de Archeologia dell'Architettura para referirse a una tradición de estudios sobre arquitectura basada no tanto en los estilos y cánones estéticos o en fuentes escritas e iconográficas de la arquitectura cuanto en sus caracteres constructivos y en las transformaciones de los edificios $^{17}$.

— En el mundo anglosajón, los estudios centrados en arquitectura a partir de una perspectiva arqueológica han conformado siempre un ámbito de investigación de sólida tradición historiográfica al que se reconoce también como Archaeology of Architecture y en el que caben enfoques muy diversos: desde los precursores que investigaron la arquitectura monumental del Próximo Oriente a las primeras formulaciones de la arqueología de los asentamientos o las propuestas procesuales más ortodoxas de la household archaeology, pero también los enunciados críticos y renovadores del postprocesualismo, las investigaciones sobre arquitectura vernácula norteamericana o británica, las aportaciones que desde la etnoarqueología permiten establecer comparaciones de alto valor interpretativo, las propuestas procedentes de los campos de la semiótica y el spatial syntax (profusamente utilizadas en la Arqueología del Paisaje) o los estudios proxémicos sobre la territorialidad y los distintos estándares culturales de espacio interpersonal, deudores estos últimos de tempranas aportaciones procedentes de la antropología ${ }^{18}$.

- De una manera similar, en Latinoamérica se hace mención también a la Arqueología de la Arquitectura para referirse genéricamente a las investigaciones arqueológicas sobre arquitectura, independientemente de sus intereses temáticos o ideológicos: estén referidas a la época prehispánica, colonial o contemporánea, se ocupen de la arquitectura monumental o doméstica, atiendan a la identificación de patrones de asentamiento, roles, funcionalidades, significados y/o articulación del paisaje, estén ejecutadas en el contexto rehabilitador de la Habana Vieja o en el proceso de recuperación del patrimonio incaico, denuncien el uso de los espacios construidos como medios de dominación

${ }_{17}$ Mannoni, T. (1990), Archeologia dell'Architettura, Noticiario di Archeologia Medievale, 54, pp. 28ss.

${ }^{18}$ Steadman, S. (1996), Recent research in the archaeology of architecture: beyond the foundations, Journal of Archaeological Research, vol. 4, n. ${ }^{\circ}$ 1, pp. 51-93. ideológicos o permitan poner al desnudo la cruel represión de las dictaduras en el Cono Sur ${ }^{19}$.

Esta aparente «promiscuidad» epistemológica, lejos de ser considerada como una culpa postmoderna que es preciso expiar con urgencia antes de proceder a una «vuelta al orden", debe ser vista como un proceso dinámico y creativo en el que hay que profundizar, prestando más atención a otras sensibilidades nacidas del pensamiento crítico y corrigiendo algunas inercias del pasado. Pero, para ello la AA debería prestar especial atención a las edificaciones en uso o susceptibles de estarlo, a aquellos espacios generados por el ser humano que, siendo simultáneamente «depositarios de las racionalidades que nos han precedido $»^{20}$ y poderosos recursos de carácter cultural y económico, corren el riesgo de desaparecer ante el crecimiento imparable a nivel planetario de aglomeraciones urbanas colosales o de ser «reciclados y/o refuncionalizados» con criterios difícilmente reversibles.

$\mathrm{Y}$ es en este contexto en que la AA del siglo XXI debe asumir su responsabilidad y su compromiso. En una época de globalización en la que las propuestas formales y explicativas se parecen cada vez más entre sí, la reivindicación de las texturas biográficas y sus especificidades contextuales resulta un ejercicio esperanzador y necesario. Puede decirse, en este sentido, que la AA configura un campo de juego abierto a cuantos les interesa el espacio construido como herencia de pasado pero también como recurso para el futuro, como depósito de memorias históricas, archivos estratigráficos, como elenco de técnicas constructivas, compendio de dimensiones simbólicas y significantes, reflejo de vivencias, conflictos y vivencias sociales, en definitiva como topografía de las complejas constelaciones cotidianas de la sociedad.

Recibido: 10 de noviembre de 2008

Aceptado: 13 de enero de 2009

\footnotetext{
19 Funari, P. y Zarankin, P. (2003), A social archaeology of housing from a Latin American perspective: a case study. Journal of Social Archaeology, Plenum-Kluwer, New Cork, vol. 3:1, pp. 23-45; Zarankin, A. y Niro, C., (2006), La materialización del sadismo; Arqueología de la arquitectura de los Centros Clandestinos de Detención de la dictadura militar argentina (1976-1983), en Funari, P. y Zarankin, A. (eds.), Arqueología de la represión y la resistencia en América Latina en la era de las dictaduras (décadas de 1960-1980), Córdoba., pp. 59-182.

${ }^{20}$ Criado, F. (2001), La Memoria y su Huella, Claves de Razón Práctica, 115, pp. 36-43.
} 